type of evidence (in vitro, in vivo, clinical trial, etc.). Subsequently, a clinical trial database (clinicaltrials.gov and WHOICTRP) search was performed to generate a list of registered trials in cervical cancer with drugs from our databases.

Result(s)* We queried 534 drugs from our drug databases. Of these, 169 drugs had at least one relevant abstract or registered trial in cervical cancer. Ninety-three drugs had at least human data available with 52 drugs evaluated in registered trials. Forty-two drugs had at most in vitro data.

All 169 drugs were assessed for strength of scientific rationale, feasibility for integration in cervical cancer standard of care, evidence of radiosensitisation and an assessment of the availability of the drug for clinical trials. Out of these 169 drugs, we present 5 examples, i.e. nelfinavir, plerixafor, valproate with hydralazine, sonidegib and cetuximab (table 1) of potential candidates out of 39 that have been prioritised for further investigation.

Conclusion* This study has identified potential candidates that are worth evaluating in cervical cancer. Although many drugs warrant additional preclinical and clinical investigation, we are exploring the possibility of conducting international collaborative multi-arm trials with one or several of these drugs.

\section{OUTCOMES OF MANAGEMENT OF LOCALLY ADVANCED CERVICAL CANCER, NATIONAL CANCER INSTITUTE EXPERIENCE, CAIRO UNIVERSITY}

${ }^{1} \mathrm{~T}$ Mohammed ${ }^{*},{ }^{1} \mathrm{M}$ Elnaggar, ${ }^{2} \mathrm{AS}$ Fouad, ${ }^{1} \mathrm{R}$ Emad, ${ }^{3} \mathrm{D}$ Negm ELdin. ${ }^{1}$ National Cancer Institute, Cairo university, Radiation Oncology , Cairo, Egypt; ${ }^{2}$ Cairo university, Clinical Oncology, Cairo, Egypt; ${ }^{3}$ National Cancer Institute, Cairo university, Statistics, Cairo, Egypt

\subsection{6/ijgc-2021-ESGO.13}

Introduction/Background* Cervical cancer is the 4th most common cancer affecting females with $85 \%$ of cases occurring in developing countries. There is limited data available in the literature about locally advanced cervical cancer management outcomes from Egypt. This is the first and the largest study to describe locally advanced cervical cancer treatment outcomes from Cairo University National Cancer Institute (NCI), the largest tertiary center for cancer in Egypt.

Methodology A retrospective study was conducted including 160 patients with pathologically proven cervical cancer, locally advanced disease (FIGO stage IIB till IVA) who presented to gynecology group, Radiation Oncology Department, NCI from 2013 to 2017. Data were collected retrospectively from patients' medical records. Demographic, clinicopathological,

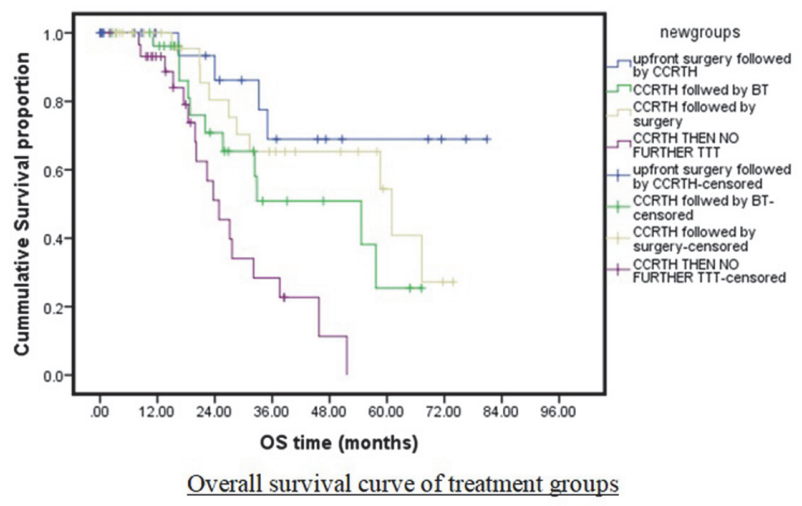

Abstarct 148 Figure 1 Overall survival curve of treatment groups treatment, and survival outcome data were retrieved. Survival analysis was estimated using the Kaplan-Meier method and compared using the log-rank test.

Result(s)* Data analysis showed a great disparity in management plans. Local control (LC) was achieved in $65.1 \%$ of the patients, and $31 \%$ had metastatic disease progression. Noncompliance to treatment was seen in $18.8 \%$ of the patients. Three years overall survival (OS) and five years OS were $45.6 \%$ and $35 \%$ respectively. Non-compliant patients had significantly lower 3 years OS $(28.4 \%, \mathrm{P}<0.001)$. The most common modality of treatment was concurrent chemoradiation therapy (CCRTH) followed by radical surgery. There was no significant difference in OS, LC, and time to the distant metastasis between the different treatment modalities.

Conclusion* Locally advanced cervical cancer management represents a challenging burden in developing countries like Egypt. Patient compliance was found to be the most important factor affecting survival in our population. Proper assessment of the factors causing low compliance should be properly evaluated. Strict follow-up and improving patient compliance are essential to achieve a favorable outcome.

\section{PHASE 3 RECURRENT/METASTATIC CERVICAL CARCINOMA TRIAL: SUBGROUP EFFICACY ANALYSIS OF CEMIPLIMAB VERSUS INDIVIDUAL INVESTIGATOR'S CHOICE CHEMOTHERAPY}

${ }^{1} \mathrm{D}$ Lorusso, ${ }^{2}$ Vergote, ${ }^{3} \mathrm{~A}$ Oaknin, ${ }^{4} \mathrm{KS}$ Tewari, ${ }^{5} \mathrm{AC}$ De Melo, ${ }^{6} \mathrm{HS}$ Kim, ${ }^{7} \mathrm{YM}$ Kim, ${ }^{8} \mathrm{~A}$ Lisyanskaya, ${ }^{9} \mathrm{~F}$ Damian, ${ }^{10} \mathrm{CL}$ Chang, ${ }^{11} \mathrm{D}$ Rischin, ${ }^{12} \mathrm{~S}$ Takahashi, ${ }^{13} \mathrm{D}$ Ramone, ${ }^{14} \mathrm{~J}$ Pikiel, ${ }^{15} \mathrm{EM}$ Guerra Alía, ${ }^{16} \mathrm{~J} \mathrm{LI},{ }^{16} \mathrm{~S}$ Jamil, ${ }^{16} \mathrm{M}$ Mathias, ${ }^{16} \mathrm{MG}$ Fury, ${ }^{17} \mathrm{BJ}$ Monk. ${ }^{1}$ Fondazione Policlinico Universitario A Gemelli IRCCS and Catholic University of Sacred Heart, Italy; ${ }^{2}$ University Hospitals, Leuven, KU Leuven, Leuven, Belgium; ${ }^{3}$ Gynaecologic Cancer Programme, Vall d'Hebron Institute of Oncology (VHIO), Hospital Universitari Vall d'Hebron, Vall d'Hebron Barcelona Hospital Campus, Barcelona, Spain; ${ }^{4}$ University of California, Irvine, Invine, USA; ${ }^{5}$ Brazilian National Cancer Institute, Rio de Janeiro, Brazil; ${ }^{6}$ Seoul National University College of Medicine, Seoul, Korea, Rep. of South; ${ }^{7}$ Asan Medical Center, University of Ulsan, Seoul, Korea, Rep. of South; ${ }^{8}$ St. Petersburg State Budgetary Institution of Healthcare, St. Petersburg, Russian Federation; ${ }^{9}$ Hospital Sao Lucas PUCRS, Porto Alegre, Brazil; ${ }^{10}$ MacKay Memorial Hospital, Taipei, Taiwan; ${ }^{11}$ Department of Medical Oncology, Peter MacCallum Cancer Centre, Melbourne, Australia; ${ }^{12}$ The Cancer Institute Hospital of JFCR, Tokyo, Japan; ${ }^{13}$ Barretos Cancer Hospital (Pio XII Foundation), Barretos, Brazil; ${ }^{14}$ Szpitale Pomorskie, Gdynia, Poland; ${ }^{15}$ Medical Oncology Department, Hospital Universitario Ramón y Cajal, Madrid, Spain; ${ }^{16}$ Regeneron Pharmaceuticals, Inc., Tarrytown, USA; ${ }^{17}$ Arizona Oncology (US Oncology Network) University of Arizona, Creighton University, Phoenix, USA

\subsection{6/ijgc-2021-ESG0.14}

Introduction/Background* There is no standard of care regimen in the second-line setting for women with recurrent/metastatic (R/M) cervical carcinoma. Cemiplimab was recently shown to significantly improve overall survival (OS) compared with investigator's choice (IC) chemotherapy in patients with $\mathrm{R} / \mathrm{M}$ cervical cancer after first-line platinum-based chemotherapy (NCT03257267; ESMO-VP-2021). We present a preplanned exploratory subgroup analysis comparing cemiplimab to individual IC chemotherapy options.

Methodology EMPOWER-Cervical 1/GOG-3016/ENGOT-cx9 is an open-label, randomised (1:1), multi-centre, Phase 3 clinical trial of anti-programmed cell death (PD)-1 cemiplimab vs IC single agent chemotherapy in $\mathrm{R} / \mathrm{M}$ cervical cancer that has progressed after first-line platinum-based treatment. The selection of single-agent chemotherapy by the investigator (gemcitabine, pemetrexed, vinorelbine, topotecan or irinotecan) was not protocol-defined, but the regimen had to be 


\section{Abstract 164 Table 1}

\begin{tabular}{|c|c|c|c|c|c|}
\hline \multirow{2}{*}{$\begin{array}{l}\text { Cemiplimab } \\
\text { vs } \\
\text { Individual IC } \\
\text { chemotherapy }\end{array}$} & \multicolumn{5}{|c|}{ Investigator choice chemotherapy prior to randomisation } \\
\hline & $\begin{array}{l}\text { Pemetrexed } \\
(n=119 \text { vs 111) }\end{array}$ & $\begin{array}{l}\text { Topotecan } \\
\text { (n=20 vs 21) }\end{array}$ & $\begin{array}{c}\text { Irinotecan } \\
(n=26 \text { vs } 19)\end{array}$ & $\begin{array}{c}\text { Gemcitabine } \\
(n=108 \text { vs 121) }\end{array}$ & $\begin{array}{l}\text { Vinorelbine } \\
\text { ( } n=31 \text { vs } 32 \text { ) }\end{array}$ \\
\hline Median OS & $\begin{array}{c}12.5(7.5-15.3) \\
\text { vs } \\
7.7(6.4-9.8) \\
\text { HR; } 0.71 \\
(0.52-0.98)\end{array}$ & $\begin{array}{c}7.0(3.9-15.0) \\
\text { vs } \\
6.5(4.4-8.8) \\
\\
\text { HR; } 0.78 \\
(0.31-1.96)\end{array}$ & $\begin{array}{c}15.8(11.2-N E) \\
\text { vs } \\
11.8(6.9-14.9) \\
\text { HR; } 0.69 \\
(0.28-1.70)\end{array}$ & $\begin{array}{c}10.7(9.2-13.3) \\
\text { vs } \\
9.0(7.0-10.6) \\
\text { HR; } 0.76 \\
(0.54-1.06)\end{array}$ & $\begin{array}{c}10.3(3.4-22.8) \\
\text { vS } \\
7.6(5.2-13.2) \\
\text { HR; } 0.77 \\
(0.40-1.48)\end{array}$ \\
\hline Median PFS & $\begin{array}{c}3.0(2.3-4.2) \\
\text { vs } \\
2.9(2.6-3.7) \\
\text { HR; } 0.70 \\
(0.52-0.94)\end{array}$ & $\begin{array}{c}2.2(1.3-4.1) \\
\text { vs } \\
2.3(1.7-5.4) \\
\text { HR; } 0.90 \\
(0.43-1.90)\end{array}$ & $\begin{array}{c}6.9(1.9-13.8) \\
\text { vs } \\
4.2(1.6-8.3) \\
\text { HR; } 0.77 \\
(0.34-1.72)\end{array}$ & $\begin{array}{c}2.8(2.6-4.3) \\
\text { vs } \\
2.8(2.1-3.9) \\
\text { HR; } 0.73 \\
(0.54-0.97)\end{array}$ & $\begin{array}{c}1.5(1.4-2.7) \\
\text { vs } \\
2.8(1.5-4.1) \\
H R ; 1.21 \\
(0.70-2.09)\end{array}$ \\
\hline ORR & $\begin{array}{c}16.0(9.9-23.8) \\
\text { vs } \\
6.3(2.6-12.6)\end{array}$ & $\begin{array}{c}15.0(3.2-37.9) \\
\text { vs } \\
4.8(0.1-23.8)\end{array}$ & $\begin{array}{c}23.1(9.0-43.6) \\
\text { vs } \\
15.8(3.4-39.6)\end{array}$ & $\begin{array}{c}17.6(10.9-26.1) \\
\text { vs } \\
5.0(1.8-10.5)\end{array}$ & $\begin{array}{c}9.7(2.0-25.8) \\
\text { Vs } \\
6.3(0.8-20.8)\end{array}$ \\
\hline \multicolumn{6}{|c|}{$\begin{array}{l}\text { Data shown by individual investigator choice of chemotherapy selected prior to randomisation in } \\
\text { cemiplimab versus chemotherapy arms. } \\
\text { OS and PFS data shown as months, } 95 \% \mathrm{Cl} \text {; ORR data shown as } \%, 95 \% \mathrm{Cl} \text {. } \\
\mathrm{Cl} \text {, confidence interval; HR, hazard ratio; } \mathrm{NE} \text {, not evaluable. }\end{array}$} \\
\hline
\end{tabular}

chosen prior to randomisation. Adult females (age $\geq 18$ years) were enrolled regardless of PD-ligand 1 expression and received cemiplimab $350 \mathrm{mg}$ intravenously every 3 weeks or IC chemotherapy for up to 96 weeks; and were stratified by histology (squamous cell carcinoma/adenocarcinoma or adenosquamous), geographic region (North America/Asia/rest of world), prior bevacizumab, and ECOG performance status (0/1). Primary endpoint was OS. Additional endpoints included progression-free survival (PFS), objective response rate (ORR), duration of response, quality of life and safety. Data cutoff was 4 January 2021.

Result(s)* A total of 608 patients were randomised: 304 to cemiplimab and 304 to IC chemotherapy (gemcitabine, $\mathrm{n}=121$; premetrexed, $\mathrm{n}=111$; vinorelbine, $\mathrm{n}=32$; topotecan, $\mathrm{n}=21$; irinotecan, $\mathrm{n}=19$ ) across geographic regions and histologies. Median duration of study follow-up (range) was 4.8 months (0.0-25.9) for the overall population. At second interim analysis, the trial was stopped early for efficacy. OS, PFS and ORR (table 1) demonstrated improvements with cemiplimab vs each IC chemotherapy treatment similar to those observed with cemiplimab vs pooled IC chemotherapy.

Conclusion* Improvements in OS, PFS and ORR with cemiplimab trended consistently with the results for the overall population regardless of IC chemotherapy drug.

\section{DYNAMIC DOSE FRACTIONATION OF HDR- BRACHYTHERAPY AT PREOPERATIVE IRRADIATION OF CERVICAL CANCER PATIENTS}

V Sukhin*, H Hranovska, O Sukhina, K Nemaltsova. Grigoriev Institute for medical Radiology and Oncology NAMS of Ukraine, Oncogynecology, Kharkov, Ukraine

10.1136/ijgc-2021-ESGO.15
Introduction/Background* The direct influence of irradiation on cervical cancer can be realized by brachytherapy (BT). We have developed methodic of dynamic dose fractionation of brachytherapy, which determined the relevance of this investigation.

The aim of this study is efficacy improvement of combined treatment of cervical cancer patients, by application of high dose-rate brachytherapy (HDR) by the method of dynamic dose fractionation as a first step of preoperative course of radiochemotherapy.

Methodology There were enrolled 54 cervical cancer patients with primary stages IB - IIA (T1b-2aNxM0). All the patients were divided into 2 groups. BT was performed by device "MultiSource», and external beam radiation therapy (EBRT) by «Clinac $600 \mathrm{C}$ », with chemomodification agent cisplatin 40 $\mathrm{mg} / \mathrm{m} 2$ weekly.

Group 1 included 34 patients, whose treatment was started with two sessions of BT (step 1) - the first one with single dose of $7 \mathrm{~Gy}$, the second one - of $5 \mathrm{~Gy}$, and then EBRT (20 Gy) up to the total dose of 32/23 Gy (step 2).

Group 2 included 20 patients, whose treatment was started with EBRT (20 Gy) - step 1, with sequential two sessions of BT with each single dose of 5 Gy (step 2), up to the total dose of 30/22.5 Gy.

The follow-up period was 3-26 months, mean - 17.2 months.

Result(s)* The effectiveness of dynamic dose fractionation HDR-BT was proved by complete tumor regression (pathomorphosis grade IV) in $35.3 \%$ of 34 patients: $50.0 \%$ of stage IB patients and $36.4 \%$ - stage IIA. In group 2, there was detected only partial tumor regression (pathomorphosis of grade II-III) in all the patients. The relapsed disease was detected in $1(6.7 \%)$ patient of Group 2 at follow-up before 1 year. 